\title{
THE MEASUREMENT OF ELECTRICAL OSCILLATIONS IN THE RECEIVING ANTENNA
}

\author{
By L. W. Austin
}

In another article ${ }^{1}$ it has been shown that the perikon detector can be standardized by comparing it with a thermo-element in a circuit to which it is coupled. If the thermo-element is calibrated so that the numerical value of the oscillating currents in the second circuit is known, then for the given conditions of frequency and coupling the perikon may be used for quantitative measurement of very small currents in the circuit to which it is coupled. This method has been developed for use in determining the numerical value of the currents in a wireless antenna when signals are being received.

The figure shows the connections used in this laboratory for this purpose. Here A E is the antenna circuit, with the inductances $\mathrm{L}_{2}$ and $\mathrm{L}_{3}$ for tuning and coupling. Below the inductance $\mathrm{L}_{3}$ is a tellurium-constantan thermo-element ${ }^{2}$ of ${ }^{5}$ ohms resistance attached to a galvanometer $\mathrm{G}_{2}$ of $8 \mathrm{ohms}$ resistance giving I $\mathrm{mm}$ for 1.810-8 amp. Between the thermo-element and earth a variable air condenser $\mathrm{C}_{2}$ of o.oor mf capacity may be connected for tuning purposes when the received signals are of very short wave length. The detector circuit consists of an inductance $L_{4}$, a stopping condenser $\mathrm{K}$ of $0.04 \mathrm{mf}$ capacity, and the perikon detector $\mathrm{D}$, with its galvanometer $\mathrm{G}$, of $2000 \mathrm{ohms}$ resistance having a sensitiveness 1.28 IO- $^{9}$ amp per $\mathrm{mm}$ of scale deflection.

Before the measurements are begun the thermo-element must first be calibrated with high-frequency currents by comparison with

1 This Bulletin, 6, p. 530; rgro.

${ }^{2}$ This Bulletin, 7, p. 3 OI; I9II. 
a sensitive hot wire ammeter read by mirror and scale. ${ }^{3}$ The resistance of the ammeter used in this experiment is $15 \mathrm{ohms}$, and at I meter scale distance I milliampere gives an appreciable deflection. With the circuits connected as shown in the figure, the antenna is tuned to the incoming signals, which for purposes of measurement should preferably be long dashes, and the coupling between $\mathrm{L}_{3}$ and $\mathrm{L}_{4}$ adjusted so that the galvanometer attached to

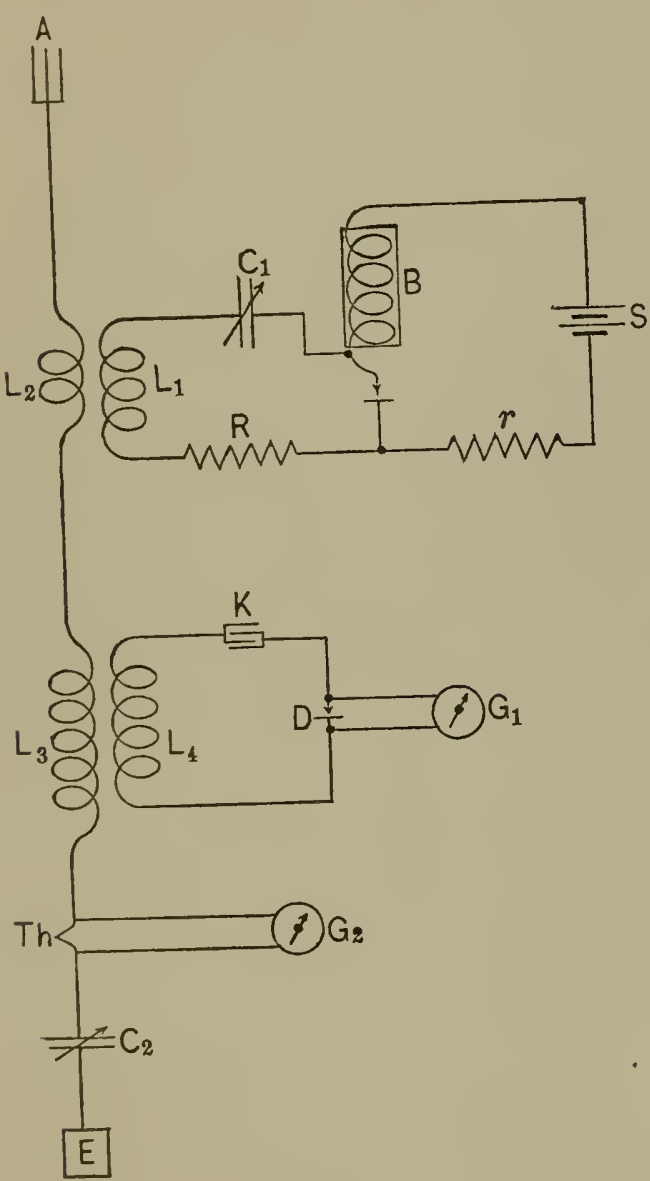

Fig. 1 the perikon gives a maximum deflection. ${ }^{4}$ When the signals have ceased, the buzzer-exciter circuit $\mathrm{L}_{1} \mathrm{C}_{1}$ is adjusted to resonance with the antenna circuit and coupled to it just closely enough so that a readable deflection is produced on the thermoelement galvanometer, while a large deflection is produced on the galvanometer attached to the perikon. The ratio of these deflections enables us at once to calculate the number of microamperes flowing in the antenna corresponding to any given deflection of the galvanometer, assuming that the deflections are proportional to the square of the current. The error in this assumption can be safely considered to be less than the errors of observation due to the fluc-

tuations of the incoming signals themselves, provided the inductive reactance of the untuned circuit be kept less than the resistance of the detector. ${ }^{5}$ Still greater accuracy may be obtained by adjusting the exciter circuit used in the comparison of the thermo-element and perikon to the same decrement as that of the

${ }^{3}$ Electrical World, 49, p. 308, 1907.

4 The coupling is made just loose enough so that the deflection begins to fall.

${ }^{5}$ Zenneck, Leitfaden der drahtlosen Telegraphie, p. 78 . 
sending station. This can easily be done by throwing the antenna out of tune while the signals are being received, so that the deflections of the perikon galvanometer are reduced to one-half. A finewire resistance $\mathrm{R}$ is then introduced into the exciter circuit until the same variation in the tuning of the antenna reduces the deflections due to the exciter to one-half. The exciter circuit then represents fully the sending station. This method also permits us to determine directly the numerical value of the decrement of the incoming waves. As a matter of fact, the errors in measurement of current due to differences between the damping of the exciter and of the sending station will be small if the decrement of the exciter be set anywhere from 0.15 to 0.3 , since the variation in the ratio of the currents in the antenna and untuned detector circuits depends very little on the sending damping except when this is extremely small.

If the effective resistance of the receiving circuit as a whole be known, the amount of the received energy can be calculated, thus giving an opportunity for experimental determination of the ratio of radiated and received energy under different circumstances and at different distances.

The galvanometer used with the perikon is considerably more sensitive than any telephone, for long dashes it gives about 3 millimeters deflection for the weakest signals audible in the best telephones in the laboratory. This makes it possible to make measurements with fair accuracy on any signals which are detectable with the ordinary receiving apparatus. ${ }^{6}$

In regard to the accuracy of the method, of course it must be admitted that it depends on two exterpolation calibrations, but careful measurements indicate that the proportionality of the galvanometer deflection and square of the current both in the case of the thermo-element and the perikon is quite perfect enough for the present purpose.

\footnotetext{
${ }^{6}$ Measurements on faint signals can of course only be made when atmospheric disturbances are absent.
} 
In the following table are given the data of a number of measurements of signals received from various stations: ${ }^{7}$

\begin{tabular}{|c|c|c|c|c|c|c|c|c|}
\hline Sending Station & $\begin{array}{l}\text { Rated } \\
\text { Power }\end{array}$ & $\begin{array}{c}\text { Wave } \\
\text { Lengths }\end{array}$ & $\begin{array}{c}\text { Approxi- } \\
\text { mate } \\
\text { Dis- } \\
\text { tance }\end{array}$ & $\begin{array}{l}\text { Perikon } \\
\text { Deflec- } \\
\text { tion }\end{array}$ & $\begin{array}{c}\text { Ratio } \\
\text { Perikon } \\
\text { to } \\
\text { Thermo- } \\
\text { element }\end{array}$ & $\begin{array}{c}\text { Re- } \\
\text { ceived } \\
\text { Cur- } \\
\text { rent }\end{array}$ & \begin{tabular}{|c|} 
Effec- \\
tive Re- \\
ceiving \\
Resist- \\
ance
\end{tabular} & $\begin{array}{c}\text { Re- } \\
\text { ceived } \\
\text { Energy }\end{array}$ \\
\hline & $\mathrm{kw}$ & m & miles & $\mathrm{mm}$ & & $\begin{array}{l}10-6 \\
\text { amp }\end{array}$ & ohms & $\begin{array}{c}10-8 \\
\text { watts }\end{array}$ \\
\hline Philadelphia (Navy Yard). & 3 & 750 & 100 & 32 & 457 & 56.3 & 25 & 8 \\
\hline Brant Rock.......... & 60 & 3750 & 350 & 330 & 1280 & 108 & 80 & 93.5 \\
\hline $\begin{array}{l}\text { U. S. S. Salem (at New } \\
\text { York) } \ldots \ldots\end{array}$ & 10 & 1000 & 185 & 100 & 540 & 91 & 38 & 31.5 \\
\hline $\begin{array}{l}\text { U. S. S. Birmingham (at } \\
\text { sea) } \ldots \ldots \ldots \ldots\end{array}$ & 10 & 1000 & 300 & 115 & 540 & 98.3 & 38 & 36.5 \\
\hline Washington (Navy Yard).. & 2 & 900 & 6 & \multicolumn{2}{|c|}{$\begin{array}{l}\text { Read directly } \\
\text { on thermo- } \\
\text { element. }\end{array}$} & 1400 & 25 & 4900 \\
\hline
\end{tabular}

$1 \mathrm{~mm}$ on thermo-element galvanometer $=213 \cdot 10^{-6} \mathrm{amp} \mathrm{A.} \mathrm{C}$.

The table is self-explanatory. The higher land absorption is well shown in the cases of the Salem and the Birmingham. With the same power and approximately the same amount of energy radiated, the Birmingham delivered more energy at the receiving station at a distance of 300 miles than the Salem at 185 , the path of the Salem's radiation being all the way overland, while the Birmingham's was for more than two-thirds of the way oversea.

The Birmingham's radiated energy may be calculated as foliows: The height of the flat top antenna was approximately 40 meters and the wave length Ioo meters; from the Hertz radiation formula ${ }^{8}$

$$
R=\mathrm{I} 600 \frac{h^{2}}{\lambda^{2}}=2: 57 \mathrm{ohms}
$$

'The antenna current was 33 amperes.

The radiated enery

$$
E=33^{2} \times 2.57=2.8 .10^{3} \text { watts. }
$$

${ }^{7}$ All the measurements were made during the daytime.

${ }^{8}$ See Rüdenburg, Ann. d. Phys., 25, p. 446; 1908 . 
The ratio of received to radiated energy

$$
\eta=\frac{36 \cdot 5 \cdot 10^{-8}}{2.8 \cdot 10^{3}}=1 \cdot 30 \cdot 10^{-10}
$$

For stronger signals the received energy may, of course, be measured directly on the thermoelement in the antenna, the perikon circuit being removed or coupled so loosely that no appreciable energy is taken up. By the last arrangement watch can be kept by means of a telephone attached to the perikon to see that no station or other disturbance comes in to affect the measurements.

By this method the following results were obtained from the station at the Washington Navy Yard, 6 miles away:

Received current at the Bureau of Standards $I=1.4 \cdot 10^{-3}$ amp.

High frequency resistance of receiving antenna $R=25^{\circ} \mathrm{ohms}$. The received energy $E=I^{2} \mathrm{R}=4 \cdot 9 \cdot \mathrm{IO}^{-5}$ watts.

The navy yard station, rated at $2 \mathrm{~K} \mathrm{~W}$, has a wave length of 900 meters and its flat top antenna has a height of 55 meters. From the radiation formula, $R=5.92$ ohms. The current in the antenna during the experiment was $\mathrm{s} 3 \mathrm{amp}$. Hence the radiated energy

$$
E=\mathrm{I} \cdot \mathrm{IO}^{3} \text { watts. }
$$

The ratio of energy received to that sent

$$
\eta=\frac{4 \cdot 9 \cdot 1 \mathrm{O}^{-5}}{\mathrm{I} \cdot 1 \mathrm{O}^{3}}=4 \cdot 9 \cdot \mathrm{IO}^{-8}
$$

This ratio, considering the short distance, is very small and is to be explained by the fact that the path of the waves lay practically all the way over the city of Washington.

U. S. NAVAL Wireless TelegRaphic Laboratory.

Washington, October I, IOIO. $7 \mathrm{Ir} 3^{\circ}{ }^{\circ}-\mathrm{II}-\mathrm{II}$ 